\title{
Transvaginal Ultrasound Measurement of Cervical Length and Posterior Cervical Angle versus Bishop Scoring in Assessment of Induction of Labour
}

\author{
Mohamed Mohamed Gibreil, Adel Aly Elboghdady, \\ Ahmed Mohamed Samy AL-Bohy* \\ Obstetrics and Gynecology Department, Faculty of Medicine, Al-Azhar University \\ *Corresponding author: Ahmed Mohamed Samy AL-Bohy, E-mail: dr.ahmed_bohy@yahoo.com
}

\section{ABSTRACT}

Background: Induction of labour is a widely used intervention on the modern labor. The Bishop score, since its description in 1964, remains the gold standard for assessing favorability for induction of labor. However, the preinduction 'favorability' of the cervix as assessed by the Bishop score is very subjective and several studies have demonstrated a poor predictive value for the outcome of induction especially in women with a low Bishop score.

Aim of the work: The objective of the study was to evaluate the Transvaginal ultrasonographic measurements in predicting the success of induction of labour.

Patients and Methods: In this study 70 women 35-42 weeks pregnancy underwent induction of labor. Before induction a digital examination of the cervix was performed \& the Bishop score noted. Cervical length, posterior cervical angle \& cervical funneling were then assessed by a transvaginal ultrasound.

Results \& conclusion: successful induction correlated significantly with the Bishop score and ultrasonographically measured cervical length, and the posterior cervical angel and ultrasound measurements were suggested to be better than the Bishop score in prediction of successful vaginal delivery.

\section{INTRODUCTION}

Induction of labor is defined as an intervention designed to artificially initiate uterine contractions leading to progressive dilatation and effacement of the cervix and birth of the baby ${ }^{(1)}$. Induction of labor is indicated when benefits to the mother or the fetus outweigh those of continuing the pregnancy such as post-dated pregnancy, premature rupture of the membranes before onset of labor, maternal diseases such as diabetes mellitus, hypertension with pregnancy, or fetal growth restriction; these are the most common indications for induction of labour ${ }^{(2)}$.

Approximately $20 \%$ of pregnant women undergo induction of labor around term. However, not all of these inductions result in vaginal delivery, and some result in emergency Cesarean sections ${ }^{(3)}$.

Transvaginal ultrasonography is a known objective method for assessing cervical length. It is not a sophisticated procedure to be done in obstetric units and clinics. Attempts have been made in the past to use transvaginal ultrasonography for prediction of type of delivery, and efforts have been made to explore if its predictive value is higher than that of the Bishop score or not. However, controversial results have been published, and not enough evidence is available to consider it as a strong alternative to the Bishop score. Measurement of cervical length and the presence of cervical funneling by transvaginal ultrasonography have

been used widely for the prediction of preterm delivery in patients at risk for or with preterm labor $^{(4)}$.

\section{AIM OF THE WORK}

The objective of the study was to evaluate ultrasonographic measured cervical length and posterior cervical angle in predicting successful labour induction as alternative method to Bishop Score.

\section{PATIENTS AND METHODS}

This was a prospective randomized study which was conducted on 70 pregnant lady not in labor indicated for termination of pregnancy who were admitted to ObstetricGynecological Dept. at Sayed Galal Hospital, Al-Azhar University from July 2017 till March 2018 with informed written consent.

All were recruited according to the inclusive criteria.

\section{Inclusion criteria:}

1. Age between 18-37 years.

2. Singleton pregnancy.

3. 35-42 weeks gestation.

4. Living fetus.

5. Cephalic presentation.

Exclusion criteria:

1. Extremes of age (below 17 and above 38).

2. Fetal macrosomia (more than 4500).

3. Malpresentation.

4. Dead fetus. 
5. Multifetal pregnancy.

6. Oligohydramnios.

7. Polyhydraminos.

8. Pre-induction non reassuring non stress test (NST).

9. Any degree of placenta Previa and/or vasaprevia.

10. Women diagnosed with a major degree of cephalopelvic disproportion by standard clinical tests.

11.Previous operations on the cervix (e.g. cautery, cerclage, cervical amputation or conization).

12.Patients already in active labor on admission.

13. Any contraindication to vaginal delivery.

Indications for labor induction were:

a) Postdate pregnancy.

b) Prelabor rupture of membranes.

c) Term pregnancy for mother with controlled medical disorder (PIH, controlled DM, PET, etc)

\section{Methods:}

All patients included in the study were subjected to the following:

Pre induction evaluation:

1. Informed written consent.

2. Full history taking:

Personal history: with special focus on maternal age.

Present History: with special focus on:

- Warning symptoms as (headache, visual symptoms, edema of the face and fingers, excessive vomiting, epigastric pain, pain in the loin, watery vaginal discharge, vaginal bleeding, reduced fetal movements, lower abdominal pain and any medications).

- Obstetric history: e.g. any obstetric complications in last pregnancies e.g., ICU admission, failure of induction.

\section{Gravidity and parity.}

Menstrual history: 1 st day of the last menstrual period, or early $\mathrm{u} / \mathrm{s}$ for accurate pregnancy dating.

Medical and surgical history: e.g. HTN, diabetes or previous operations on the cervix (e.g. cautery, cerclage, cervical amputation or conization) or any surgical operations.

\section{General examination:}

\section{a. Vital signs.}

b. BMI.

\section{Abdominal examination:}

a. Assessment of fundal level, fetal heart sounds.

b. Presence of scars of any previous abdominal or pelvic surgeries.

\section{Vaginal examination:}

a. To assess the Bishop score of the cervix by assessment of:

- Cervical dilation.

- Cervical effacement.

- Cervical consistency.

- Cervical position.

- Fetal station.

- Cervical length.

- Condition of the membranes.

- Pelvic adequacy.

- Fetal Presentation.

Bishop Scoring system used for assessment of inducibility ${ }^{(5)}$.

\begin{tabular}{|l|l|l|l|l|l|}
\hline \multirow{2}{*}{ Parameter } & \multicolumn{3}{|c|}{ Ocore } & \multicolumn{1}{c|}{$\mathbf{2}$} & \multicolumn{1}{|c|}{ Description } \\
\cline { 2 - 5 } & Posterior & Intermediate & Anterior & - & $\begin{array}{l}\text { The position of the cervix varies between } \\
\text { individual women: facing, } \\
\text { anterior,intermediate and posterior } \\
\text { locations. }\end{array}$ \\
\hline Consistency & Firm & Intermediate & Soft & - & . \\
\hline Effacement & $0-30 \%$ & $31-50 \%$ & $51-80 \%$ & $>80 \%$ & \\
\hline Dilatation & $0 \mathrm{~cm}$ & $1-2 \mathrm{~cm}$ & $3-4 \mathrm{~cm}$ & $>5 \mathrm{~cm}$ & The length of the stretched cervix. \\
\hline Fetal station & -3 & -2 & $-1,0$ & $+1,+2$ & $\begin{array}{l}\text { Fetal station describes the position of the } \\
\text { foetus' head in relation to the distance from } \\
\text { the ischial spine. Negative numbers indicate } \\
\text { that the head is inside above the ischial } \\
\text { spine. }\end{array}$ \\
\hline
\end{tabular}

\section{Scoring:}


Each component was given a score of 0 to 2 or 0 to 3 . The highest possible score was 13 .

\section{Interpretation:}

- A score of 5 or less suggests that labour is unlikely to start without induction.

- A score of 9 or more indicates that labour will most likely be spontaneously. A low Bishop's score often indicates that induction is unlikely to be successful.

- Some sources indicated that only a score of 8 or greater is reliably predictive of a successful induction.

\section{Ultrasound assessment:}

\section{a. Transabdominal:}

Complete real time transabdominal ultrasonographic examination including confirmation of gestational age, fetal number, viability, presentation, estimated fetal weight, position and site of placenta, amount of liquor, and to exclude congenital anomalies.

\section{b. Transvaginal:}
a. Cervical length.
b. Cervical funneling.
c. Posterior cervical angle.

\section{A. The cervical length was measured from internal to external os.}

\section{B. Presence of funneling was recorded.}

C. Posterior cervical angle was measured in a sagittal plane at the level of the internal os, as the angle between an imaginary line traversing the cervical canal and another tangential to the posterior uterine wall at its junction with the internal os. Values were approximated to the nearest degree. In case of a funneled or an excessively curved cervix, the angle was assessed at the junction of the line measuring the cervical length and the posterior uterine wall.

\section{RESULTS}

1. Indications for induction of labour:

Table (1): Indications for induction of labour:

\begin{tabular}{|l|l|c|c|}
\hline \multicolumn{2}{|c|}{ Variable } & Count & \% of total patients \\
\hline \multirow{3}{*}{ Indications for induction: } & Pass Date & 28 & $40.0 \%$ \\
\cline { 2 - 4 } & ROM & 20 & $28.6 \%$ \\
\cline { 2 - 4 } & PIH & 14 & $20.0 \%$ \\
\cline { 2 - 4 } & Diabetic & 8 & $11.4 \%$ \\
\hline
\end{tabular}

The most common cause of induction was passed date (28 patients) 25 of them have delivered vaginally. The 2 nd common cause was ROM (20 patients) 13 of them have delivered vaginally, then PIH (14 patients) 8 of them have delivered vaginally, then gestational diabetes ( 8 pregnant women) 3 of them delivered vaginally.

\section{Mode of delivery among the study group:}

Table (2): Indications for induction of labour and mode of delivery:

\begin{tabular}{|c|c|c|c|c|c|c|}
\hline \multirow{3}{*}{\multicolumn{2}{|c|}{ Variable }} & \multicolumn{4}{|c|}{ MODE OF DELIVERY } & \multirow{3}{*}{$P$ value } \\
\hline & & \multicolumn{2}{|c|}{ NVD } & \multicolumn{2}{|c|}{ C.S } & \\
\hline & & Count & $\%$ & Count & $\%$ & \\
\hline \multirow{4}{*}{$\begin{array}{l}\text { Indications for } \\
\text { induction: }\end{array}$} & Pass Date & 25 & $51.0 \%$ & 3 & $14.3 \%$ & \multirow{4}{*}{0.011} \\
\hline & ROM & 13 & $26.5 \%$ & 7 & $33.3 \%$ & \\
\hline & PIH & 8 & $16.3 \%$ & 6 & $28.6 \%$ & \\
\hline & Diabetic & 3 & $6.1 \%$ & 5 & $23.8 \%$ & \\
\hline
\end{tabular}

It was found that an indication for induction of labour was significantly correlated to successful induction ( $\mathrm{p}$ value 0.011 ).

Table (3): Mode of delivery and percentage:

\begin{tabular}{|l|l|c|c|}
\hline \multicolumn{2}{|c|}{ Variable } & Count & \% of total patients \\
\hline \multirow{2}{*}{ Mode of delivery } & NVD & 49 & $70.0 \%$ \\
\cline { 2 - 4 } & C.S & 21 & $30.0 \%$ \\
\hline
\end{tabular}

49 pregnant women were delivered vaginally and 21 were delivered by cesarean section. Indications of C.S. were failed induction (patient received 4 doses of misoprostol 25 microgram with 6 
hours interval and no cervical dilatation \& effacement were noted), failure to progress, fetal distress or abruption placentae.

\section{Bishop score and ultrasonographic criteria:}

Table (4): Bishop score, ultrasonographic criteria and mode of delivery:

\begin{tabular}{|c|c|c|c|c|c|c|c|c|c|c|c|}
\hline \multirow{3}{*}{ Parameter } & \multicolumn{10}{|c|}{ Mode of Delivery } & \multirow{3}{*}{$\begin{array}{c}\mathbf{P} \\
\text { value }\end{array}$} \\
\hline & \multicolumn{5}{|c|}{ NVD } & \multicolumn{5}{|c|}{ C.S } & \\
\hline & Mean & SD & Median & Minimum & Maximum & Mean & SD & Median & Minimum & Maximum & \\
\hline $\begin{array}{l}\text { C.A } \\
\text { (Cervical } \\
\text { Angle) }\end{array}$ & 122.74 & 15.75 & 125.00 & 75.00 & 150.00 & 90.43 & 11.86 & 89.80 & 70.00 & 130.00 & $\begin{array}{c}< \\
0.001\end{array}$ \\
\hline \begin{tabular}{|l|} 
C.L (Cervical \\
Length) \\
\end{tabular} & 27.94 & 5.04 & 29.00 & 15.00 & 40.00 & 36.71 & 5.63 & 38.00 & 22.00 & 45.00 & $\begin{array}{c}< \\
0.001\end{array}$ \\
\hline Bishop score & 6.86 & 2.21 & 6.00 & .00 & 10.00 & 4.57 & 1.63 & 5.00 & .00 & 8.00 & $\begin{array}{c}< \\
0.001 \\
\end{array}$ \\
\hline
\end{tabular}

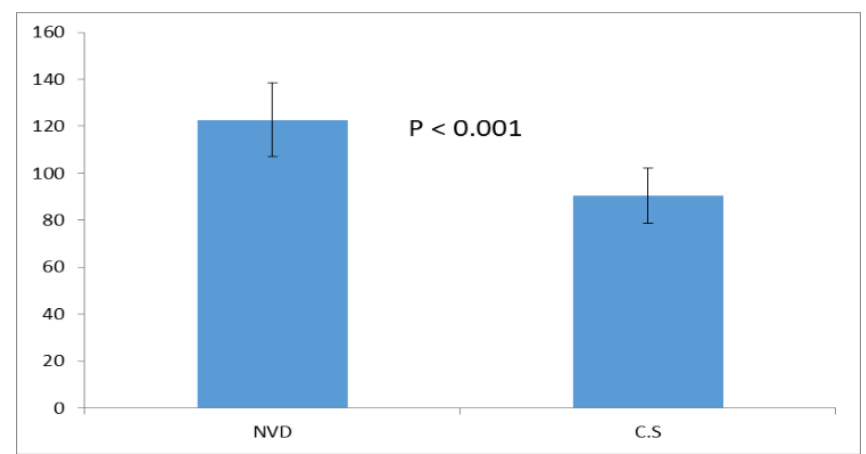

Figure (1): Cervical angle and mode of delivery.

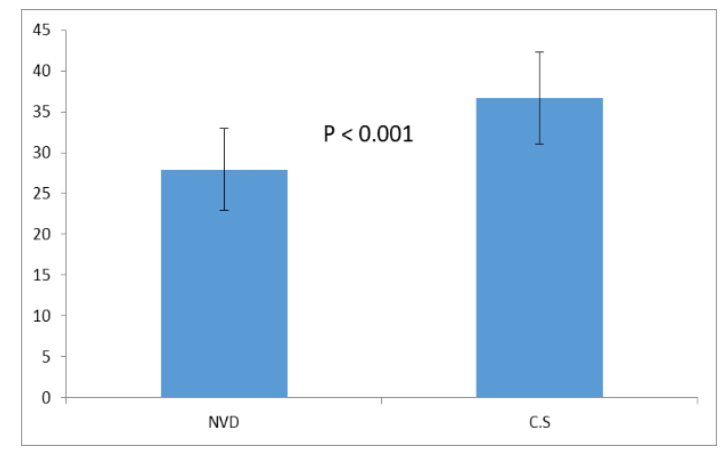

Figure (2): Cervical Length and mode of delivery

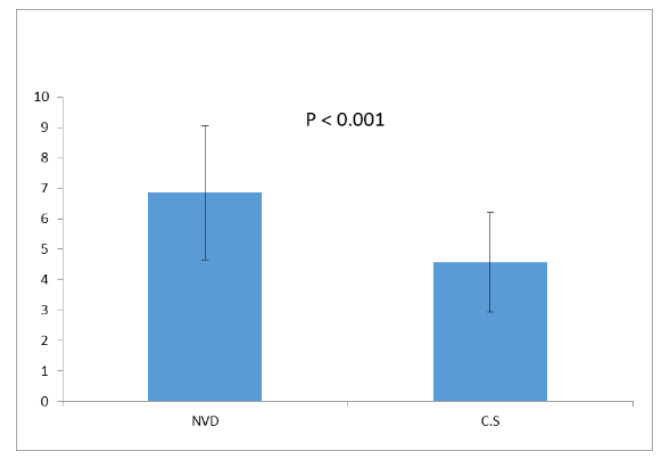

Figure (3): Bishop Score and mode of delivery

The mean posterior cervical angle in patients delivered vaginally was $122.74 \pm 15.75$ degrees while the mean posterior cervical angle in patients delivered by C.S. was $90.43 \pm 11.86$ degrees.

The mean cervical length in patients delivered vaginally was $27.94 \pm 5.04 \mathrm{~mm}$ while the mean cervical length in patients delivered by C.S. was $36.71 \pm 5.63 \mathrm{~mm}$.

The mean Bishop score in patients delivered vaginally was $6.86 \pm 2.21$ while the mean Bishop score in patients delivered by C.S. was $4.57 \pm 1.63$.

Table (5): Accuracy of Bishop Score Vs posterior cervical angle and cervical length in prediction of successful induction: 
Transvaginal Ultrasound Measurement of Cervical Length and Posterior Cervical...

\begin{tabular}{|c|c|c|c|c|c|c|c|}
\hline \multirow{2}{*}{$\begin{array}{l}\text { Test Result } \\
\text { Variable(s) }\end{array}$} & \multirow{2}{*}{$\begin{array}{c}\text { Area under } \\
\text { curve }\end{array}$} & \multirow{2}{*}{$\begin{array}{c}P \\
\text { value }\end{array}$} & \multicolumn{2}{|c|}{$\begin{array}{l}\text { 95\% Confidence } \\
\text { Interval }\end{array}$} & \multirow{2}{*}{$\begin{array}{l}\text { Cutoff } \\
\text { value }\end{array}$} & \multirow{2}{*}{$\begin{array}{c}\text { Sensitivity } \\
(\%)\end{array}$} & \multirow{2}{*}{$\begin{array}{l}\text { Specificity } \\
(\%)\end{array}$} \\
\hline & & & $\begin{array}{l}\text { Lower } \\
\text { Bound }\end{array}$ & $\begin{array}{l}\text { Upper } \\
\text { Bound }\end{array}$ & & & \\
\hline $\begin{array}{l}\text { C.A (Cervical } \\
\text { Angle) }\end{array}$ & .939 & $<0.001$ & .870 & 1.008 & 99.75 & 91.8 & 90.5 \\
\hline $\begin{array}{l}\text { C.L (Cervical } \\
\text { Length) }\end{array}$ & .872 & $<0.001$ & .765 & .979 & 34.5 & 91.8 & 81 \\
\hline Bishop Score & .821 & $<0.001$ & .717 & .925 & 5.5 & 73.5 & 81 \\
\hline
\end{tabular}

- Using a cut-off value of posterior cervical angle 99.75 degree degree showed Sensitivity $\mathbf{9 1 . 8} \%$, Specificity $90.5 \%$.

- Using a cut-off value of cervical length $34.5 \mathrm{~mm}$ showed sensitivity $91.8 \%$, specificity $81 \%$.

- Using a cut-off value Bishop Score 5.5 showed Sensitivity $\mathbf{7 3 . 5} \%$, Specificity $\mathbf{8 1} \%$.

We found that posterior cervical angle was a more specific predictor of successful vaginal delivery compared to cervical length and bishop score. And it was as sensitive as cervical length and more sensitive compared to bishop score in prediction of successful vaginal delivery.

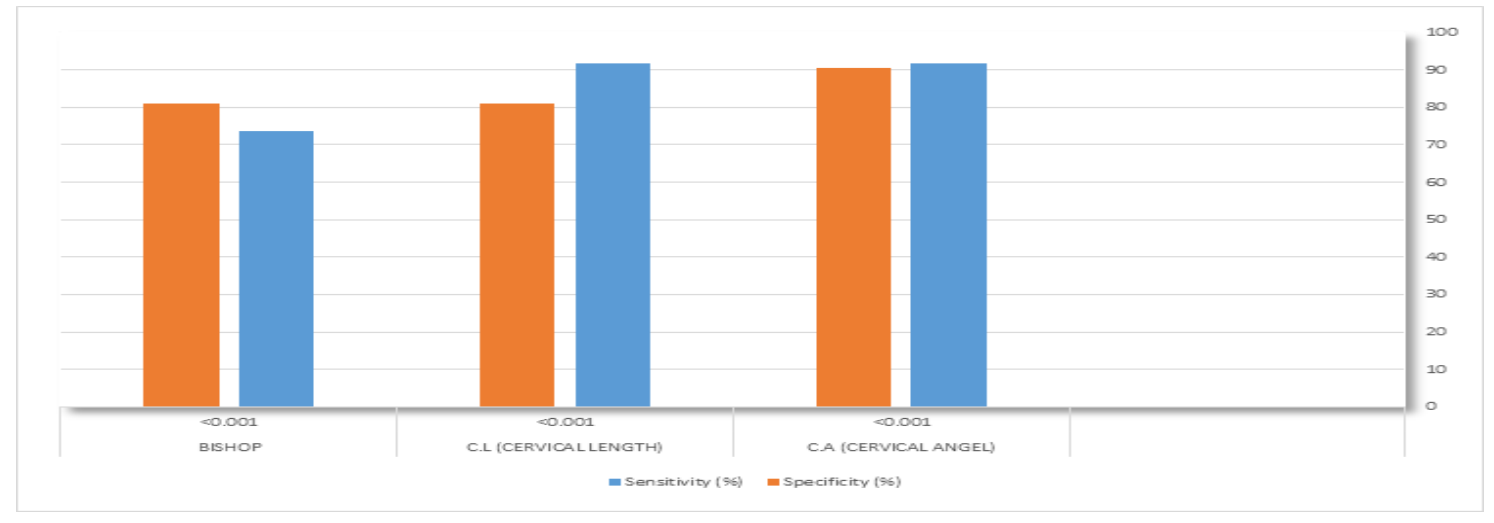

Figure (4): Sensitivity and Specificity of Bishop Score Vs posterior cervical angle and cervical length in prediction of successful induction

\section{DISCUSSION}

In modern obstetrical practice induction of labour has been tried in one of every five deliveries for various maternal and/or fetal indications and incidence is gradually rising ${ }^{(6)}$.

Induction of labour is performed in about $20 \%$ of all pregnancies and successful induction is reported to be related to cervical characteristics, or 'ripeness' ${ }^{(7)}$.

Traditionally, the Bishop score has been used to assess the favorability of the cervix (8).

However, the preinduction 'favorability' of the cervix as assessed by the Bishop score is very subjective and several studies have demonstrated a poor predictive value for the outcome of induction especially in women with a low Bishop score ${ }^{(9)}$.
Recently there is a surge of interest in finding alternative measures to predict the success of induction.

Transvaginal ultrasonographic measurement of cervical length may be a more objective method for assessing cervical status $(10,11)$.

The aim of this study was to determine the relationship between preinduction ultrasonographic measurements and Bishop score in prediction of successful vaginal delivery. In this study,70 pregnant women 35-42 weeks gestational age undergoing induction of labour due to passed date, ROM, PIH and gestational diabetes by using $25 \mu \mathrm{g}$ misoprostol vaginally. The dose was repeated at 6 hours interval for maximum 24 hours. Prior to induction of labor patients underwent cervical assessment with transvaginal sonography followed by digital cervical assessment using Bishop Score. 
In this study (70\%) of our 70 participants were delivered vaginally and (30\%) women were delivered by C.S.

This study found that successful induction of labour correlated significantly with the Bishop score ( $p$ value $<0.001$ ), posterior cervical angle ( $\mathrm{p}$ value <0.001) and ultrasonographic cervical length ( $p$ value < 0.001 ). There was also statistically significant relation between GA, funneling and successful induction of labor ( $\mathrm{P}$ value 0.001$)$.

There was no statistically significant difference detected between the women with successful induction of labor to those with failed induction regarding the mean maternal $\operatorname{age}(26.10 \pm 4.08$ vs $26.81 \pm 4.17$ years),maternal BMI (27.35 vs. 26.14) and the mean neonatal birth weight (3035.24 vs $3025.71 \mathrm{~kg}$ ).

This agreed with Yang $\boldsymbol{e t}$ al..$^{(12)}$ who studied induction of labour in 105 women as they found that successful induction correlated significantly with the Bishop Score and cervical length.

In this study assessment of the cervix by Bishop score: Bishop score of 5.5 showed a sensitivity for prediction of successful induction of labor of $73.5 \%$ and specificity of $81 \%$.

And for assessment of the cervix by transvaginal ultrasound, the sensitivity for prediction of successful induction of labor was $91.8 \%$ at cervical length of $34.5 \mathrm{~mm}$ and $81 \%$ for its specificity. And the sensitivity of posterior cervical angle was $91.8 \%$ and its specificity was $90.5 \%$ at cutoff value of 99.75 degree.

So, validity of posterior cervical angle and cervical length as predictors of successful labor induction according to our study indicates that both of them were more sensitive and specific predictors of successful labor induction than the Bishop score for the prediction of successful labor induction.

Agreeing with our results, Bastani et al. ${ }^{(13)}$ studied 200 women with singleton pregnancies undergoing induction of labor at 37-42 weeks. Transvaginal ultrasound was done for all participants prior to induction. To compare the predictive value of the methods, they found cervical length measured by transvaginal ultrasonography has the potential to replace the traditional Bishop score, provided that such a facility is available when needed.
Also, Laencina et al. ${ }^{(14)}$ assessed Bishop Score by digital examination and measured cervical length by transvaginal ultrasonography in 177 women with a single pregnancy, 36-42 weeks of gestation, and a live fetus in cephalic presentation before induction of labor with both prostaglandin and oxytocin. Similar to our results they found that the Bishop Score, cervical length, and parity provided independent contribution in the prediction of the likelihood of delivering vaginally within $60 \mathrm{~h}$. Also like our result cervical length was a better predictor than the Bishop score.

Tan et al. ${ }^{(15)}$ in their prospective study that was performed on 249 women admitted for labor induction. They found that analysis of the ROC curves for cervical length and Bishop Score indicated that both were predictors of Cesarean delivery. Moreover they found that Transvaginal sonography was significantly less painful than digital examination for Bishop Score assessment.

Rane et al. ${ }^{(16)}$ found that in women undergoing induction of labor, significant independent prediction of the induction-to delivery interval within 24 hours, the likelihood of vaginal delivery within 24 hours and the likelihood of cesarean section are provided by pre-induction cervical length. Sonographic parameters were superior to the Bishop score in the prediction of the outcome of induction.

Peregrine et al. ${ }^{(17)}$ found same results when they studied induction of labour in 267 women at 36 or more weeks of gestation immediately before induction of labor. Logistic regression analysis was used to determine which factors best predicted the risk of cesarean delivery. They found that Parity, body mass index, height, and ultrasonic transvaginal cervical length $(p<0.001)$ are the most accurate parameters in predicting the risk of cesarean delivery after induction of labor.

However, in contrast to our study, Chandra et al. ${ }^{(18)}$ studied 122 women with postdated pregnancy where Transvaginal ultrasound and digital vaginal examinations were performed immediately before labor induction. Ultrasound assessments of cervical length, dilatation, and presence of funneling were compared with the components of the Bishop Score. They found no ultrasound characteristic predicted successful vaginal delivery and Bishop Score, cervical position and maternal age independently predicted vaginal delivery. 
Also, Reis et al. (19) enrolled prospectively 134 women undergoing labor induction at term caused by several obstetric conditions. All participants submitted to digital examination, and transvaginal ultrasound for measurement of the cervical length and detection of funneling. Only obstetric history and digital examination predicted accurately vaginal delivery within 24 hours and were independently associated with labor duration. Ultrasound measurements of cervical length failed to predict accurately the outcome of induced labor.

In another study:

Rozenberg et al. ${ }^{(20)}$ in their study of 166 women induced with prostaglandins found the Bishop score to be better than cervical length for predicting successful outcome of induced labor.

\section{REFERENCES:}

1. Royal College of obstetricians and Gynaecologists (RCOG) (2001): Inductionof labour. In Evidence-based Clinical Guideline Number 9. RCOG Press: London. Available at: https:// www. researchgate.

net/ publication/266045914_RCOG_Evidencebased_Clinical_ Guidelines_ Induction_ of_labour.

2. Bennett KA, Crane JM, Shea $P$ et al. (2004): First trimester ultrasound screening is effective in reducing postterm labor induction rates: a randomized controlled trial. Am J Obstet Gynecol., 190(4):10771081.

3. Groenevelda Y, Bohnenb A, Van heusdenc A (2010): Cervical length measured by transvaginal ultrasonography versus Bishop score to predict successful labour induction in term pregnancies. F, V \& V In Ob \& Gyn., 2 (3): 187-193.

4. Leitich $\mathrm{H}$, Egarter $\mathrm{C}$, Kaider $\mathrm{A}$, Hohlagschwandtner M, Berghammer P, Husslein P (1999): Cervicovaginal fetal fibronectin as a marker for preterm delivery: a meta-analysis. Am. J. Obstet. Gynecol., 180(5): 1169-1176.

5. Cunningham FG, Gant NF, Leveno KJ, Gilstrap LC III, Hauth JC, Wenstrom $\mathbf{K D}$ (2005): Induction of labor. eds: Williams obstetrics. New York: McGraw hill, 22nd edition. Available at: http:// www. scirp. org/(S (vtj3fa45qm1ean45vvffcz55))/ reference/ References Papers. aspx? Reference ID= 1409850 .

6. Crane JM (2006): Transvaginal ultrasound cervical length and successful labor induction: a systematic review. Obstetrics \& Gynecology, 107(4):60.

7. Groenevelda Y, Bohnenb A, Van Heusdenc A (2010): Cervical length measured by transvaginal ultrasonography versus Bishop score to predict successful labour induction in term pregnancies. F, V \& V In OBGyn., 2 (3): 187-193.

8. Bishop EH (1964): Pelvic scoring for elective induction. Obstetrics \& Gynecology, 24(2):266-268.

9. Selhi $M$ and Surapaneni T (2010): Pre induction sonographic measurement of cervical length: An adjunct to Bishop Score?, Fernandez Hospital Journal of Perinatalogy, 1(2): 20-35.

10. Rozenberg P (1999): Transvaginal Ultrasound of the Cervix: hope in the Fight against Premature delivery. J Radiol., 80(5): 421-9.

11. Pandis GK, Papageorghiou AT, Ramanathan MO, Thompson OM, Nicolaides KH (2001): Preinduction sonographic measurement of cervical length in the prediction of successful induction of labour. Ultrasound Obstet Gynecol., 18(6): 623-628.

12. Yang SH, Cheong RR, Jong HK (2004): Trans-vaginal ultrasonography for cervical length assessment before induction of labour. J Ultrasound Med., 23(2): 375-382.

13. Bastani P, Hamdi K, Abasalizadeh F, Pourmousa P, Ghatrehsamani F (2011): Transvaginal ultrasonography compared with Bishop score for predicting cesarean section after induction of labor. International journal of women's health, 3(1):277-280.

14. Laencina AM, Sánchez FG, Gimenez JH, Martínez MS, Martínez JA, Vizcaíno V (2007): Comparison of ultrasonographic cervical length and the Bishop score in predicting successful labor induction. Acta obstetricia et gynecologica Scandinavica, 86(7):799-804. 
15. Tan PC, Vallikkannu N, Suguna S, Quek KF, Hassan J (2007): Transvaginal sonographic measurement of cervical length vs. Bishop score in labor induction at term: tolerability and prediction of Cesarean delivery. Ultrasound in Obstetrics and Gynecology, 29(5):568-573.

16. Rane SM, Guirgis RR, Higgins $B$, Nicolaides KH (2003): Pre-induction sonographic measurement of cervical length in prolonged pregnancy: The effect of parity in the prediction of the need for cesarean section. Ultrasound Obstet Gynecol., 22(1):45-48.

17. Peregrine E, O'Brien $P$, Omar $R$, et al (2006): Clinical and ultrasound parameters to product the risk of cesarean delivery after induction of labor. Obstet Gynecol., 107(2): 227-33.
18. Chandra S, Crane JM, Hutchens D, Young DC (2001): Transvaginal ultrasound and digital examination in predicting successful labor induction. Obstet Gynecol., 97(1):2-6.

19. Reis FM, Gervasi MT, Florio $P$ et al (2003): Prediction of successful induction of labor at term: Role of clinical history, digital examination, ultrasound assessment of the cervix, and fetal fibronectin assay. Am J Obstet Gynecol., 189(5): 1361-1367.

20. Rozenberg P, Gillet A, Ville Y (2005): Transvaginal sonographic examination of the cervix in asymptomatic pregnant women: Review of the literature. Ultrasound Obstet Gynecol., 19(3):302311. 